\title{
HIPPOCAMPAL RHYTHMIC, SLOW ACTIVITY AND HEART RATE UNDER FOOD AND WATER DEPRIVATION IN THE RAT
}

\author{
TSUnEO IWASAKI and ShINkURo IWAHARA ${ }^{1,2)}$
}

\section{Tokyo University of Education}

Primary drives such as hunger and thirst have been believed to produce a central arousal state, electrophysiologically associated with low voltage, high frequency patterns from cortical placements, and this arousal state is a nonspecific component of drive, apart from a drivespecific component (cf. 8). According to the activation theory of emotion proposed by LindSLEY (12), the limbic system, especially the hippocampus, is involved in the tonic or sustaining drive state. In a recent article, JARRARD (9) has contended that the hippocampus gives a significant influence on nonspecific changes in activation or arousal, related to incentive motivation (hunger and thirst).

In connection with the effect of food or water deprivation upon hippocampal electrical activity, some divergent results have been reported. MatsudA (13) failed to find any noticeable changes in the hippocampal electrical activity of hungry as compared with satiated rats, whereas HockMAN ( 5 ) found that food deprivation produced an increase in frequency and decrease in amplitude from the hippocampal lead in rats. In a recent investigation, RoUTTENBERG (14) reported that food deprivation augmented the duration of appearance of hippocampal rhythmic wave of the rat.

The hippocampal electrical activity is generally accepted to have

1) The authors are indebted to Mr. ShujI Yoshida for his help in preparation of this manuscript.

2) Requests for reprints should be sent to Tsuneo Iwasaki, Department of Psychology, Tokyo University of Education, 3-29-1 Otsuka, Tokyo, Japan 112. 
two characteristic components; rhythmic, slow or theta activity and desynchronized or fast activity. The rhythmic activity of the hippocampus has been reported to shift its frequency depending upon the degree of central excitatory state along the general arousal continuum $(2,10,15)$. In the present study, an effort was made to clarify any possible changes in the frequency of rhythmic, slow activities as a function of food and water deprivation.

As to peripheral changes, DOERR and HoKANSON ( 3 ) has stated that food deprivation produces a decceleration of heart rate, such that heart rate and deprivation level are inversely related. The present study was designed to obtain recordings of heart rate in addition to those of hippocampal rhythmic activity in focd and water deprived rats, and to get informations, if any, about relationships between the two variables.

\section{METHOD}

Subjects: Ss were 5 naive male albino rats of the Wistar-Imamichi strain. Their body weight ranged from 138 to $440 \mathrm{~g}$ at the time of the electrode implantation.

Procedure: Each $S$ was anesthetized with intraperitoneal pentobarbital injection $(40 \mathrm{mg} / \mathrm{kg})$, and placed in a stereotaxic instrument. A monopolar electrode was implanted in the ventral hippocampus with the coordinate of $2.7 \mathrm{~mm}$ anterior to the frontal zero, $4.0 \mathrm{~mm}$ lateral to the midline, and $2.0 \mathrm{~mm}$ deeper to the horizontal zero plane according to the brain map of KöNIG and KLIPPEL (11). The electrode was made from stainless steel wire with $0.2 \mathrm{~mm}$ in diameter, insulated except at the tip. The reference electrode, stainless screw with $1.0 \mathrm{~mm}$ in diameter, was fixed onto the nasal bone. In order to record the electromyogram (EMG) and electrocardiogram (EKG) simultaneously, a pair of stainless needle electrode were inserted in posterior cervical muscles.

About ten days after the operation, $S$ was placed in the observation box $(40 \times$ $30 \times 70 \mathrm{~cm}$ ) with a front glass wall, and the hippocampal electrical activity, EMG and EKG were recorded with the aid of a polygraph (San-ei, IAll-10). Each $S$ was given an adaptation time for about $30 \mathrm{~min}$ on each day before the recording was begun. The recording was made for six and a half hours in the afternoon for all $S s$ except D-7 rat, for which the recording lasted for 2 hours. Each $S$ was subjected to control sessions for at least 3 days, during which food and 
water were given ad libitum except for the recording period, being followed by the deprivation sessions for at least 3 days, during which both food and water were deprived. Electrode placements were histologically verified in all $S s$ at the completion of the experiment.

Data Analysis : Recordings of visually identifiable hippocampal theta waves were sampled for consecutive $5 \mathrm{sec}$ as one epoch. Thirty such samples were obtained for each session as randomly as possible. Mean frequency per sec was calculated based on the number of theta waves for each sample. In addition, the number of heart rates was counted for each of the samples.

\section{Results}

The relative frequency distributions of mean theta frequencies in sec during the waking period (WAKING) are shown for $2 \mathrm{Ss}$ (D-O, D-7 rat) in the
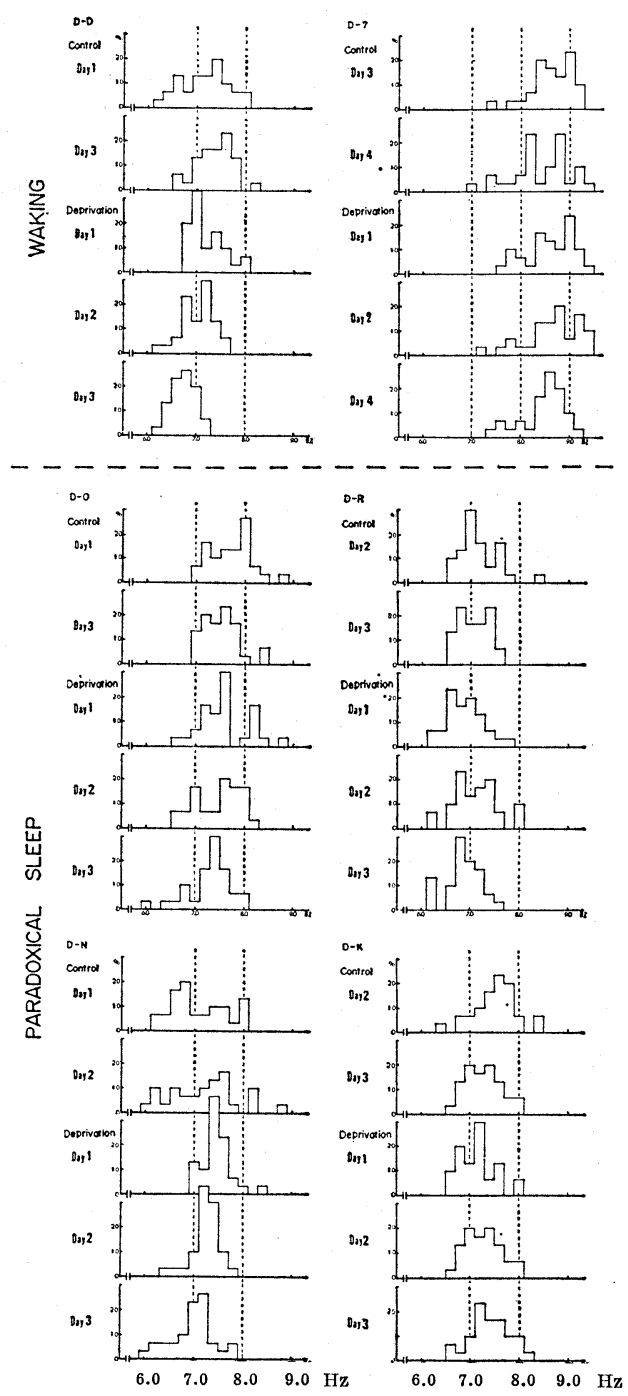

Fig. 1. Effect of food and water deprivation upon relative frequency distributions of mean theta frequencies per sec. 
upper half of Fig. 1. Sufficient or 30 samples cculd be collected only for these $S s$. The frequency histograms tended to become more concentrated in both cases as deprivation increased. The grand means of theta frequency and of heart rate, respectively, are summarized in Fig. 2. The effect of focd and water deprivation upon the two variables

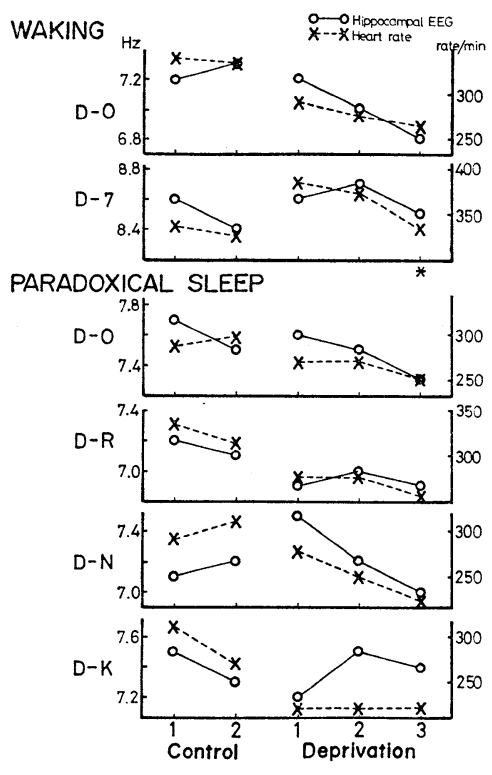

Fig. 2. Effect of food and water deprivation upon theta frequency and heart rate.

An asterisk on the panel of D-7 rat indicates that data presented are those for day 4 because data for day 3 are not available for technical errors. appears to be different for the two $S s$, in that both variables decreased under deprivation in the $\mathrm{D}-\mathrm{O}$ rat while they increased in the D-7 rat in comparison with the control data. A closer inspection of the polygraphical (EEG or behavioral) recordings revealed that the $\mathrm{D}-\mathrm{O}$ rat tended to show less bodily movements, whereas the D-7 rat moved more vigorously during the deprivation sessions. These differences of bodily movements may be partly responsible for the different results in the two $S s$. It should be emphasized, however, that theta frequency and heart rate decreased in the 4 th deprivation day in the $\mathrm{D}-7$ rat, while its bodily movements remained increased as compared with the control sessions. Thus, it is suggested from the present data that both theta frequency and heart rate decrease as the duration of deprivation becom- 
es longer (at least for 3 days).

In order to avoid possible influences of bodily movements upon theta frequency and heart rate, similar analyses were conducted during paradoxical sleep. The neural mechanisms responsible for generating theta activity have been suggested to be basically the same in the waking and the paradoxical sleep (16). The results are shown in the lower parts of Fig. 1 and 2, respectively. The distributions of theta frequencies tended to become more concentrated with deprivation days (Fig. 1). The grand mean theta frequency increased in some $S s$ but decreased in others, while heart rate decreased in all $S s$, during the early sessions of deprivation. During the later sessions of deprivation, however, theta frequency and heart rate tended to decrease for all Ss (Fig. 2). These results were comparable with those in the waking period.

It might be argued that hippocampal theta frequency and heart rate would change dependent upon the total occurrence time of the waking or paradoxical sleep stages. Table 1 shows the per cent occurrence of the waking or paradoxical sleep stages, and the per cent EEG stage does not seem to be related either to the hippocampal theta frequency or heart rate during the waking as well as the paradoxical sleep stages.

Table 1. Effect of food and water deprivation upon per cent occurrence of the EEG stage of waking or paradoxical sleep.

\begin{tabular}{l|c|cc|rrr}
\hline & S & Control & days & \multicolumn{2}{c}{ Deprivation } & days \\
\hline \multirow{3}{*}{ WAKING } & D-O & 48 & 42 & 39 & 46 & 37 \\
& D-7 & 45 & 43 & 50 & 54 & 77 \\
\hline \multirow{3}{*}{ PARADOXICAL } & D-O & 14 & 10 & 13 & 9 & 15 \\
SLEEP & D-R & 11 & 12 & 15 & 16 & 3 \\
& D-N & 14 & 9 & 14 & 13 & 14 \\
& D-K & 12 & 10 & 12 & 8 & 9 \\
\hline
\end{tabular}

Notes: Figures indicate per cent occurrence of the EEG stage of waking or paradoxical sleep during the observation on each day. 
Table 2. Correlation coefficient between hippocampal theta frequency and heart rate within day.

\begin{tabular}{l|c|cc|rrr}
\hline & $S$ & Control & days & \multicolumn{2}{c}{ Deprivation } & \multicolumn{2}{c}{ days } \\
& & 1 & 2 & 1 & 2 & 3 \\
\hline \hline \multirow{3}{*}{ WAKING } & $\mathrm{D}-\mathrm{O}$ & .59 & .11 & .37 & -.13 & .06 \\
& $\mathrm{D}-7$ & .29 & .46 & .33 & -.45 & -.07 \\
\hline \multirow{3}{*}{ PARADOXICAL } & $\mathrm{D}-\mathrm{O}$ & -.42 & .26 & -.19 & -.38 & -.21 \\
SLEEP & $\mathrm{D}-\mathrm{R}$ & -.44 & .16 & -.15 & .04 & .07 \\
& $\mathrm{D}-\mathrm{N}$ & .46 & .30 & -.30 & -.06 & .24 \\
& $\mathrm{D}-\mathrm{K}$ & -.06 & .03 & .15 & .20 & -.16 \\
\hline \hline
\end{tabular}

Notes: Mean correlation coefficients at the bottom row were calculated by the $z$-transformation method.

Further analysis was conducted concerning the relationship between the theta frequency and heart rate within the recording day(Table 2). As is seen in the last row of mean correlation coefficients in Table 2, the group mean correlation between hippocampal theta frequency and heart rate was negligible. There appear some individual differences in correlations but the difference across the subjects was significant only on the first control day $\left(\chi^{2}=27.31, d f=5 ; p<0.01\right)$.

As to the time course of hippocampal theta frequency and heart rate in each day, a representative sample (D-O rat) is presented in Fig. 3. Any consistent (decrease or increase) change either in theta frequency or heart rate was not recognized in any day during the waking as well as the paradoxical sleep.

\section{Discussion}

The results of this experiment indicated that food and water deprivation did not produce any uniform effects on hippocampal theta frequency, while heart rate decreased with deprivation for all $S s$ except for one rat, so long as deprivation lasted for 48 hours or 2 days. But as deprivation was continued for longer days (at least for three days), 

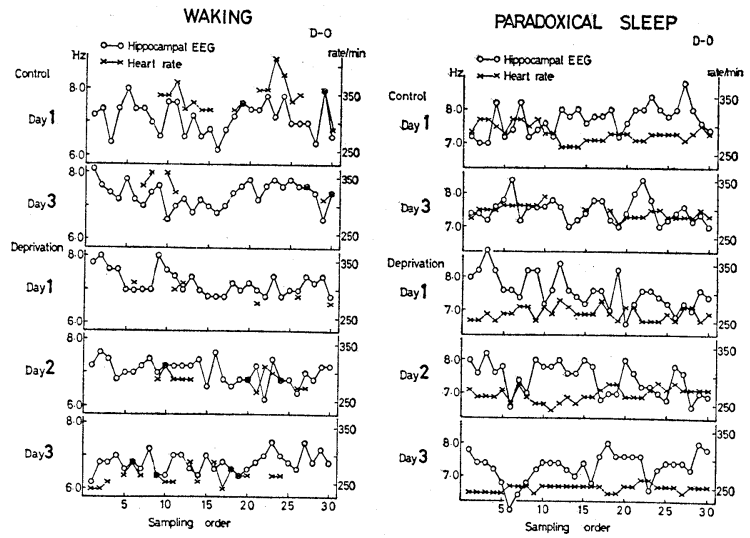

Fig. 3. Effect of food and water deprivation upon time course of theta frequency and heart rate on each control and deprivation day.

both theta frequency and heart rate seemed to decrease.

With regard to the effect of deprivation on hippocampal electrical activity, Hockman ( 5 ) reported that food deprivation resulted in an amplitude reduction of theta components accompanied by an increase in electrical components above $12 \mathrm{c} / \mathrm{sec}$. These changes in electrical activity were interpreted as consonant with an activation theory proposed by LINDSLEY (12). In contrast, RoutTENBERG (14)demonstrated that hungry rats showed a marked augmentation of hippocampal rhythmic activity, in that clearly idenfiable theta waves remained to occur for longer duration when those in the normal animals had disappeared, replaced by irregular fast activity. The RouttenBerG's results might be also explained by the activation theory (12), because hippocampal theta activity is claimed to be a correlate of central activated state such as arousal (4) and attention (1).

In RoutTenBerg's study (14), however, frequency analysis of theta activity was not conducted. Recent studies $(2,10,15)$ suggested that frequency shift of hippocampal theta wave was expected to occur 
dependent upon the central activation level. The present study specifically paid attention to any possible changes in theta frequency under food and water deprivation, but no uniform changes could be found during the 2 days of deprivation. These results may imply that frequency of hippocampal theta activity is not a direct index of tonic or sustaining drive state produced by food and water deprivation.

With longer days(at least for three days) of deprivation, hippocampal theta wave was found to decrease in frequency accompanied by a reduction of heart rate. The present finding concerning heart rate is consistent with that of Doerr and HoKAnson ( 3 ). The obtained decrease in frequency of theta wave under longer deprivation might be interpreted as a correlate of at least partial deficits in the hippocampal function, because our previous studies $(6,7)$ indicated that chlordiazepoxide produced a frequency reduction in hippocampal theta wave, and the same drug exerted in deteriorating effect on such behavior as required of an intact hippocampal functioning.

\section{SUMMARY}

The effect of food and water deprivation upon hippocampal rhythmic theta activity and heart rate were investigated in albino rats. With regard to hippocampal electrical activity, it was specifically intended in the present study to see whether frequency of theta wave would change with deprivation. The results of this experiment indicated that no uniform change in frequency of theta wave occurred during first and second days of deprivation. With longer (at least for three days) of deprivation, however, theta frequency tended to decrease for all $S s$. Heart rate was found to decrease during deprivation as compared with during control sessions. These findings were discussed in terms of an activation theory (12) and hippocampal function $(6,7)$.

\section{REFERENCES}

1. Bennett, T. L. Hippocampal theta activity and behavior-a review. Commun. Behav. Biol., 1971, 6, 37-48. 
2. Brown, B. B. Frequency and phase of hippocampal theta activity in the behaving cat. Electroenceph. clin. Neurophysiol., 1968, 24, 53-62.

3. Doerr, H. O., and Hokanson, J. E. Food deprivation, performance, and heart rate in the rat. J. comp. physiol. Psychol., 1968, 65, 227-231.

4. Green, J. D., and Ardurni, A. A. Hippocampal electrical activity in arousal. J. Neurophysiol., 1954, 17, 533-557.

5. Hockman, C. H. EEG and behavioral effects of food deprivation in the albino rat. Electroenceph. clin. Neurophysiol., 1964, 17, 420-427.

6. Iwahara, S., Oishi, H., Yamazaki, S., and SaKai, K. Effects of chlordiazepoxide upon spontaneous alternation and the hippocampal electrical activity in white rats. Psychopharmacologia (Berl.), 1972. 24, 496-507.

7. Imahara, S., and Sugimura, T. Effect of chlordiazepoxide on black-white discrimination acquisition and reversal in white rats. (In Japanese with an English abstract). Jap. J. Psychol., 1970, 41, 142-150.

8. Iwahara, S., Yang, K-M., Yamazaki, S., and Sugimura, T. Psychophysiological effects of prolonged food and water deprivation in the albino rat. Jap. Psychol. Rev., 1970, 13, 123-142.

9. Jarrard, L. E. The hippocampus and motivation. Psychol. Bull., 1973, 79, $1-12$.

10. Klemm, W. R., and Douglass, J. H. Modulation of the frequency of hippocampal rhythmic, slow activity (theta) by stimulation of other brain areas. Physiol. Behav., 1974, 12, 205-213.

11. König, J. F. R., and Klippel, R. A. The Rat Brain. A Stereotaxic Atlas of the Brain Stem. Baltimore: Williams \& Wilkins, 1963.

12. Lindsley, D. B. Psychophysiology and motivation. In M. R. Jones (Ed.), Nebraska Symposium on Motivation. Lincoln:University of Nebraska Press, 1957. Pp. 44-106.

13. Matsuda, M. Studies on the electroencephalography of the rat (3). Comparison of the EEG at different levels of food deprivation. (In Japanese with an English abstract). Ann. Animal Psychol., 1964, 14, 1-10.

14. Routtenberg, A. Hippocampal correlates of consummatory and observed behavior. Physiol. Behav., 1968, 3, 533-535.

15. Stumpf, Сн. Drug action on the electrical activity of the hippocampus. Int. Rev. Neurobiol., 1965, 8, 77-138.

16. Winson, J. Patterns of hippocampal theta rhythm in the freely moving rat. Electroenceph. clin. Neurophysiol., 1974, 36, 291-301. 